\title{
Exploring industry-university partnerships in the creation of short courses and micro-credentials
}

\author{
Rachel Fitzgerald and Henk Huijser \\ University of Queensland, Queensland University of Technology
}

This paper explores industry-university partnerships in the creation of short courses and microcredentials. It is a position paper that precedes a pilot study. We scan the higher education environment for current practices and begin to explore the notion of a more consistent and strategic approach. Partnerships refer to both industry as partners in course development, and industry as partners in developing meaningful learning experiences in the context of professional and career development. The pilot study that this paper is connected to aligns with national and international frameworks and explores university-industry partnerships, to ensure such partnerships can be leveraged to offer better value to learners with regards to workplace and lifelong learning.

Keywords: Industry Partnerships, Micro-credentials, Short Courses, Skills Development

\section{Introduction}

The global lockdown, caused by the pandemic, created an unprecedented rise in enrolments in online short courses and MOOCs with private providers (Impey, 2020). Short courses offer people a timely and flexible way to explore subjects of interest and they appeal to a variety of participants. They are also growing exponentially (AQF, 2019, Candlefox, 2020), as a wide range of participants seek to upskill or gain new knowledge. While some of this growth can be attributed to low cost, easy access through online providers, and possibly the opportunities afforded during pandemic lockdowns, it is unlikely that such courses will disappear from the landscape of skills-based education. In higher education, we are familiar with short online courses and MOOCs, which have been around for some time. There is, however, growing interest in making them part of the higher education ecosystem, as micro-credentials. Global discussion focuses on finding ways to transfer credit for such micro-credentials (AQF 2021, Nic Giolla Mhichíl et al., 2021) and the research implies that the future of such credentials requires more coherence across policy and application (Kift, 2020).

While there is much research on micro-credentials at present, it is mainly focused on the role of the university and the opportunities it presents for students; however, scholarly discourse about the role of industry partners appears to be lacking. This applies both to industry partners in the design and delivery of micro-credentials, and to industry partners who seek out micro-credentials as part of professional development for their staff. This paper evaluates the literature and considers the opportunities that micro-credentials offer, for universities and industry in partnership, in a post-COVID landscape. We evaluate to what extent micro-credentials in the higher education ecosystem afford a 'back to the future' scenario and consider what has emerged in the wake of the pandemic. We discuss the potential risks of a reactive approach to skills development, when what we should be seeking is an opportunity to develop a more strategic and coherent approach to upskilling the nation, in the face of unprecedented changes to work practices in the future (Mykelbust \& Smidt, 2021). The key to this will be working closely with industry partners to establish how they believe micro-credentials will work for them as part of a long-term strategic approach.

\section{Contextualising micro-credentials}

Micro-credentials and short courses tend to be focused, short and vocational. Unlike a higher education degree program, micro-credentials are normally self-contained units. FutureLearn, a global short course provider, describes micro-credentials as professional credentials designed to build in-demand career skills (FutureLearn, 2021). Acree (2016) suggests that micro-credentials are a means to engage in skills-based professional learning that is rigorous, yet self-paced. Candlefox (2020) similarly describes micro-credentials as short courses that enable learners to access specific knowledge and skills quickly and promotes micro-credentials as a means to upskill or enter a new industry in a time and cost-efficient way. This focus on career skills is common across providers, and short course providers' ability to create highly focused curriculum enables them to offer instant 
access that works for organisational learning and development operations (D’Orio, 2019). Micro-credentials present an innovative and flexible format that focuses on specific areas or skills and opens opportunities for flexible modularity, as well as fitting with trends of stackable credentials and the unbundling of education (Huijser \& Fitzgerald, 2020; Huijser, Fitzgerald \& Salmon, 2020). The Australian Government has identified short courses as a way to help people re-train out of industries disrupted by the pandemic (IHE, 2021), yet there has been limited research about micro-credentials in the field of career development (Boud \& Jorre de St Jorre, 2021; Healey, 2021; Gauthier, 2020). In short, micro-credentials are defined in a range of different ways, reflecting the general lack of consistency in their conceptualisation. Oliver's (2019) 'everyday use' definition is helpful in this respect: "A micro-credential is a certification of assessed learning that is less than a formal qualification" (p. 19). Keeping this definition in mind, both micro-credentials and short courses fall within the scope of this paper, which contributes to an exploratory pilot study.

Despite limited research into their impact on career development, micro-credentials are being touted as a means to enable students to develop a transcript of 'skills' that would have appeal to employers who see the value of agile and flexible learning that short courses can offer. Ralston (2020) suggests that micro-credentialing has become the preferred option for industry when it comes to workforce development, while others suggest that more work is needed around sensemaking with industry (Nic Giolla Mhichíl et al, 2021; Oliver, 2019). There is a suggestion that the advantage of short courses is their ability to focus on what is needed in the workplace in an agile manner, for example in technology areas like FinTech and AI (De Novellis, 2021). Micro-credentials also offer opportunities for lifelong learning and Carey (2015) suggests that adult learners may prefer the short, targeted micro-credential to a long-term degree program. However, this presents potential challenges, as participants often miss some of the richer elements to higher education such as critical thinking and teamwork, which are usually developed over time in a carefully designed and scaffolded manner (Carey, 2015).

\section{Opportunities for micro-credentials in a post-COVID university landscape}

The challenges related to micro-credentials present simultaneous opportunities, and a key opportunity (as well as a challenge) for universities is to develop a coherent approach to micro-credentials, without losing the attraction of flexibility for learners. Private, worldwide providers, including not-for-profit groups such as EdX and FutureLearn and for-profit developers like Coursera, Google, Udemy and LinkedIn Learning offer a vast range of short courses, open to all and accessible online. There are many more private providers in the market ready to fill any 'knowledge/skill' gaps, so it makes sense to work with, rather than compete against them. Developing strategies and road maps to work long-term with partners, rather than compete with private providers, affords opportunities to develop learning communities of multiple groups of micro-credential participants and to focus on the richer elements of learning as part of developing genuine lifelong learning skills. Ideally, such learning communities would be characterised by ongoing self-directed engagement that extends beyond the short time-span of the official micro-credential or short course. Taking a strategic approach to developing stackable credentials instead of offering all topics to all participants will make the opportunities clearer to both participants and industry partners seeking to re-skill and upskill their workforce.

Building short skills-based courses into stackable credentials also appeals to private providers. Coursera see the value of credentials as an opportunity to offer students a flexible approach to credit-bearing study that can be counted towards a future qualification (Richter, 2018). Seeing private providers as potential collaborators rather than competitors creates important opportunities. Oliver (2019) suggests that micro-credentials offer a space for a partnership model between universities and third-party providers, including industry partners. Indeed, some universities take this viewpoint and see micro-credentials as an opportunity to stay competitive, particularly against the more affordable options available on Coursera and EdX. This has seen universities like Harvard, MIT and many others, partner with private providers to offer short-form credentials, such as verified MOOCs and MicroMasters, which can be used for credit in more traditional degree programs. Micro-credentials are also useful as a recruitment tool for providers, as they can enable global brand awareness and provide a showcase opportunity with incentives to continue learning, which makes them attractive to university partners (De Novellis, 2021; Resei et al., 2019).

Private providers have already demonstrated their willingness to partner with universities to maximise on university experience and status (EdX, 2021), and universities have demonstrated a need for more agility in moving to online education (Huijser \& Fitzgerald, 2020). Yet, Ralston (2020) suggests that micro-credentials have become popular because there is increasingly less value attached to a university degree. He speculates that micro-credentials are a fad similar to the introduction of blockchain technology as an education platform and suggests that micro-credentials are pushing university curriculum towards vocational training. In response, we are not suggesting to replace traditional degrees but instead to broaden offerings by considering what 
opportunities exist to work with industry to develop strategically needed short courses that can be built into stackable credentials, as well as leveraging on and embracing the digital capability that may result from such a partnership. We further posit that collaborating with accredited universities guarantees a quality approach to skills development that will be more attractive to employers particularly as quality control is one of the biggest concerns for short courses (D'Orio, 2019). Additionally, universities can play a key role in bringing a holistic approach to skills development in a purposeful framework of career development (Healey, 2021).

\section{Risks of unstructured micro-credentials}

Having access to multiple courses of study is an exciting opportunity for many learners; however, there are risks with engaging in an 'all you can learn' smorgasbord. Online micro-credentials often feature digital certification and badges, which suit online recruitment. Social recruitment tools like LinkedIn allow users to share their achievements and skill certificates in ways that are not possible with traditional degrees (Carey, 2015; Gauthier, 2020). Healey (2021) notes that those who undertake micro-credentials may not appreciate how to express the value of the skills they accumulate in a context that supports a career strategy. This makes it critically important for those seeking careers to consider a framework approach to taking on micro-credentials (Hall-Ellis, 2016, Healey, 2021). Industry recruiters will not value a haphazard approach to skills development and are likely to be confused by unstructured approaches to learning (Gauthier, 2020). University faculties and career centres are equipped to take a more strategic view of how credits can be used to develop careers as part of a "lifelong learning ecosystem" (Kift, 2020); however, there are currently limited strategies to enable this. Seeing it as part of a lifelong learning ecosystem also draws attention to the need to clearly define what the (changing?) role of universities is into the future. As Barnett (2013) has argued, "we require, therefore, in the first place, a proliferation of ideas of the university, if only to begin to demonstrate that things could be other than they are" (p. 5). In the context of our discussion here, this presents an opportunity to partner with industry to develop collective understanding of the value of micro-credentials and to collaborate on a strategic map in ways that makes sense for future skills development for all, which taps into both career development and the development of skills and attributes that universities are traditionally good at developing. The key here is that traditional degrees still hold a lot of value, but universities need to diversify at the same time in order to address the increasing variety of learner needs and profiles in the context of Kift's (2020) "lifelong learning ecosystem". Partnerships not only contribute to a 'proliferation' of ideas but also have the potential to better align learners' needs with what university/industry partnerships are able to offer.

\section{Back to the future: Online micro-credential learning in a post-COVID landscape}

While we experienced major change during the pandemic, it is important to remember that much of this discussion predates the pandemic. Online short courses (micro-credentials) were already available, and there was already a government and industry expectation that universities deliver and assure graduate skills. However, the pandemic has reminded us of the uncertainty that we face with regard to work skills and of the importance of online education in areas of professional and skill development. The pandemic has further served to accelerate the need to look for agile strategies to support learners, to acknowledge the broad and capable competition that universities face and to look to the future and not lose momentum in engaging with industry and future learners to enable the use of micro-credentials to upskill and reskill the workforce of the future, particularly in a fastchanging job market. It is evident that people who have completed micro-credentials are keen to do more, but we must remember that one size does not fit all (Acee, 2016) and simply replicating popular micro-credentials in universities seems senseless. We suggest that universities do not need to reinvent the wheel but should instead consider how best to incorporate what private partners already provide, i.e., a model of work-based and lifelong approaches to skills-based education in partnership.

We suggest that universities should accept credentials as part of an overall framework for lifelong learning, and to co-lead on a strategic map in the upskilling or reskilling of the workforce during uncertain times. We posit that partnering with industry partners to map a strategic framework for engaging with micro-credentials affords opportunities to develop required skills for the future and also open agile opportunities for workplace learners in the form of lifelong stackable credentials. Developing a true partnership that involves co-designing and codeveloping micro-credentials makes for a good approach to deliver what industry (or rather, industries) need(s) in an uncertain future (Nic Giolla Mhichíl et al., 2021), and it would also allow for a strategic approach to aligning them with and 'plugging them into' existing degree programs in meaningful ways that take account of the diversity in learners for whom micro-credentials are suitable. 
Additionally, developing partnerships with private providers opens the door to developing quality materials at less cost to the university, while opening opportunities on a global scale through the online platforms that are available. Micro-credentials lend themselves very well to online learning, and as we have identified, recent disruption in the higher education sector has accelerated the popularity of virtual programs, particularly in the context of professional, lifelong and corporate learning (Candlefox, 2020). The digital infrastructure, including capacity and capability of university staff to deliver and facilitate micro-credentials in an online environment, may become more agile if we partner with private providers in more strategic ways. Skills-based microcredentials do not guarantee career success or employment, but as Healy (2021) reminds us, university careers services could offer support to help learners develop a narrative around the value of their micro-credentials, and universities are in a good place to help develop the learner in a much more holistic way. It is this understanding of developing balance of strengths that will allow learners to make the most of their chosen paths of education.

\section{Conclusion}

This paper has put forward a position that universities need to develop strong and meaningful partnerships with industry to develop a strategic and coherent approach to creating a mature use of micro-credentials as a means of upskilling the workforce for the future. Online micro-credentials look set to continue to grow in popularity and universities have a place in offering quality and cohesion to guide learners on how micro-credentials add value to their lifelong learning trajectory. This paper is a precursor to a study that explores university-industry partnerships and that aligns with national and international frameworks to ensure that such partnerships can be leveraged to offer better value to learners. In the first instance we will map how brokers of higher education understand the concept of short courses and microcredentials with industry partners. From this we aim to produce a map of current practice for discussion.

\section{References}

Acree, L. (2016). Seven lessons learned from implementing microcredentials. Friday Institute for Educational Innovation at the NC State University College of Education.

AQF (2019). Review of the Australian Qualifications Network. Final Report 2019. https://www.dese.gov.au/ higher-education-reviews-and-consultations/resources/review-australian-qualifications-framework-finalreport-2019

Barnett, R. (2013). Imagining the university. Routledge.

Boud, D., \& Jorre de St Jorre, T. (2021). The move to micro-credentials exposes the deficiencies of existing credentials. Journal of Teaching and Learning for Graduate Employability, 12(1), 18-20. https://ojs.deakin.edu.au/index.php/jtlge/article/view/1023/1018

Candlefox (2020). Micro-credentials in 2020: The provider handbook. https://www.candlefox.com/wpcontent/uploads/2020/09/Micro-Credentials-in-2020-\%E2\%80\%94-The-Provider-Handbook.pdf.

Carey, K (2015) Here's what will truly change higher education: online degrees that are seen as official. New York Times, 5 March. https://www.nytimes.com/2015/03/08/upshot/true-reform-in-higher-education-whenonline-degrees-are-seen-as-official.html

D’Orio, W. (2019) What's in a microcredential? Education Dive. https://credentialengine.org/wpcontent/uploads/2019/06/Whats-in-a-microcredential - _Education-Dive.pdf.

Educause (2016), Micro-credentialing. http://www.educause.edu/library/micro-credentialing.

EdX (2021) More about partnering. https://www.edx.org/schools-partners?hs-referral=navigation-menulink\#membership.

FutureLearn (2021) Microcredentials and programs https://www.futurelearn.com/programs.

Gauthier, Thomas. (2020). The value of microcredentials: The employer's perspective. The Journal of Competency-Based Education, 5(2). https://doi.org/10.1002/cbe2.1209.

Healy, M. (2021). Microcredential learners need quality careers and employability support. Journal of Teaching and Learning for Graduate Employability, 12(1). https://doi.org/10.21153/jtlge2021vol12nolart1071.

Hall-Ellis, Sylvia D. (2016). Stackable micro-credentials - a framework for the future. The Bottom Line. 29(4), 233-236. https://doi.org/10.1108/BL-02-2016-0006.

Huijser \& Fitzgerald (2020). Managing expectations and developing trust: An evaluation of a public-private partnership. Australasian Journal of Educational Technology, 36(5), 58-70. https://doi.org/10.14742/ajet.6368

Huijser, H, Fitzgerald, R. \& Salmon, G. (2020). Partnerships for scaled online learning and the unbundling of the traditional university. Australasian Journal of Educational Technology, 36(5), 1-4. https://doi.org/10.14742/ajet.6664 
IHEA (2021). 2021-22 Federal budget measures provide essential support for Australian independent higher education students and providers. https://ihea.edu.au/news/2021-22-federal-budget-measures-provideessential-support-for-australian-independent-higher-education-students-and-providers.

Impey, C. (2020, July 23) Massive online open courses see exponential growth during COVID-19 pandemic. The Conversation. https://theconversation.com/massive-online-open-courses-see-exponential-growthduring-covid-19-pandemic-141859.

Kift, S. (2021). Foreword: Future work and learning in a disrupted world: "The best chance for all." Journal of Teaching and Learning for Graduate Employability, 12(1), i-v. https://doi.org/10.21153/jtlge2021vol12nolart1015.

Mykelbust, J.P., Smidt, H. (2021) What is the role of the university in global upskilling. University World News. https://www.universityworldnews.com/post.php?story=20210129110449887.

Nic Giolla Mhichíl, M., Brown, M., Beirne, E. \& Mac Lochlainn, C. (2020). A micro-credential roadmap: Currency, cohesion and consistency. Dublin City University.

Oliver, B. (2019) Making micro-credentials work for learners, employers and providers. Deakin University. https://wordpress-ms.deakin.edu.au/dteach/wp-content/uploads/sites/103/2019/08/Making-micro-credentialswork-Oliver-Deakin-2019-full-report.pdf? ga=2.39448035.1365398763.16341565521152930570.1605467577

Ralston, S. (2021) Higher education's microcredentialing craze: A postdigital-Deweyan critique. Science and Education, 3, 83-101 https://doi.org/10.1007/s42438-020-00121-8.

Resei, C., Friedl, C., Staubitz, T., and Rohloff, T. (2019). Micro-credentials in EU and Global. Corship EU. https://www.corship.eu/wp-content/uploads/2019/07/Corship-R1.1c micro-credentials.pdf.

Richter, C. (2018) Credentials and the future of Education: Key insights from the Administrators Track at the 2018 Coursera Partners Conference Blog https://blog.coursera.org/credentials-future-education-key-insightsadministrator-track-2018-coursera-partners-conference/.

TEQSA (2018). Occasional forum series: Quality assurance of online learning. https://www.teqsa.gov.au/latestnews/publications/occasional-forum-series-quality-assurance-online-learning.

Fitzgerald, R \& Huijser, H. (2021). Exploring industry-university partnerships in the creation of short courses and micro-credentials. In Gregory, S., Warburton, S., \& Schier, M. (Eds.), Back to the Future - ASCILITE '21. Proceedings ASCILITE 2021 in Armidale (pp. 340-344). https://doi.org/10.14742/ascilite2021.0149

Note: All published papers are refereed, having undergone a double-blind peer-review process. 